\author{
Jun/2020 \\ Working Paper 20-19 \\ rcea.org/RePEc/pdf/wp20-19.pdf

\section{ENERGY CONTAGION IN THE COVID-19 CRISIS}

\author{
Reinhold Heinlein \\ University of the West of England, UK \\ Gabriella D. Legrenzi \\ University of Keele, UK \\ CESifo Research Network \\ RCEA \\ Scott M. R. Mahadeo \\ University of Portsmouth, UK
}

Copyright belongs to the author. Short sections of the text, not exceeding three paragraphs, can be used provided proper acknowledgement is given.

The Rimini Centre for Economic Analysis (RCEA) was established in March 2007. RCEA is a private, nonprofit organization dedicated to independent research in Applied and Theoretical Economics and related fields. RCEA organizes seminars and workshops, sponsors a general interest journal, the Review of Economic Analysis (REA), and organizes a biennial conference, the Rimini Conference in Economics and Finance (RCEF). Scientific work contributed by the RCEA Scholars is published in the RCEA Working Paper series.

The views expressed in this paper are those of the authors. No responsibility for them should be attributed to the Rimini Centre for Economic Analysis. 


\title{
Energy contagion in the COVID-19 crisis
}

\author{
Reinhold Heinlein ${ }^{\mathrm{a}, *}$, Gabriella D. Legrenzi ${ }^{\mathrm{b}, \mathrm{c}, \mathrm{d}}$, Scott M. R. Mahadeo ${ }^{\mathrm{e}}$ \\ ${ }^{a}$ Bristol Business School, University of the West of England, BS16 1QY, United Kingdom \\ ${ }^{b}$ Keele Business School, University of Keele, ST5 5AA, United Kingdom \\ ${ }^{c}$ CESifo Research Network \\ ${ }^{d}$ Rimini Centre for Economic Analysis \\ ${ }^{e}$ Portsmouth Business School, University of Portsmouth, PO1 3DE, United Kingdom
}

\begin{abstract}
We investigate the relationship between oil prices and stock markets of selected oil importers and oil exporters at the time of the COVID-19 pandemic. We provide evidence in favour of energy contagion, in terms of significantly higher correlations between oil and stock markets returns during turbulent phases in the oil market, for all countries in our sample. Our results are robust to different crisis datings and consistent across different segments of the assets return distributions.
\end{abstract}

Keywords: contagion; intraday data; local correlation; oil; stock markets

JEL classification: C58; G01; G15

\section{Introduction}

We analyse the relationship between oil prices and stock markets at the time of the ongoing COVID-19 global pandemic, with consequences on the world economy already forecasted as "far worse" than the Global Financial Crisis ${ }^{1}$.

Crude oil is a very influential commodity, and whilst the oil/macroeconomics nexus is well documented (see, e.g. Hamilton, 1983), the existence, sign and nature of the oil/stock market nexus is less clear-cut (see, e.g. Reboredo and Rivera-Castro (2014), Wen et al. (2012) and references therein): oil and stock market returns might present a negative correlation, given the potential of crude oil to perform a significant role in portfolio diversification, being an highly liquid and heavily traded commodity. On the other hand, crude oil prices might reflect market expectations regarding future macroeconomic variables, implying therefore a positive correlation between oil and stock returns. Furthermore, the net oil importing/exporting status of different countries seems to matter, with increasing evidence in favour of a country-specific nature of such link (see, e.g. Wang et al., 2013).

Ascertaining the nature of the oil/stock market link is particularly important for investors and policymakers, especially during extreme events. Our focus on a sample of oil importing and exporting countries across BRICS, OECD, and Scandinavian countries allows a better gauging of the worldwide impact of the current crisis.

\footnotetext{
${ }^{*}$ Corresponding author's e-mail: Reinhold.Heinlein@uwe.ac.uk

${ }^{1}$ IMF, World Economic Outlook, April 2020
} 
The concept of energy contagion, defined as a significant deepening of the oil/stock market correlations during crises in the oil market (Mahadeo et al., 2019) is particularly pertinent to gain a better insight into the oil/stock market nexus at the time of the COVID-19 pandemic and will inform our empirical application. Such definition allows us to discern between interdependence and contagion, with the former only requiring comovement across calm/crisis periods (as in Forbes and Rigobon, 2002), focussing on crisis periods in the oil market as the potential source of contagion. We note that, during our period of analysis, the crude oil market has been subject to remarkable turbulence, resulting in historically low prices².

Our empirical analysis is based on the local Gaussian correlation introduced by Tjøstheim and Hufthammer (2013) and the contagion testing in Støve et al. (2014), which allows us to examine the oil/stock market nexus at different segments of the assets return distributions.

Considering previous studies applying the local Gaussian methodology to contagion testing, Bampinas and Panagiotidis (2017) provide evidence of flight-to-quality from stocks to crude oil during different financial crises; Nguyen et al. (2020) finds contagion between energy commodities and the US stock market. Unlike Bampinas and Panagiotidis (2017) and Nguyen et al. (2020), our identification of crisis/non-crisis periods is based on the oil market, to assess its impact on the stock market of different economies, given the relative unimportance of each individual country for the global oil market.

To the best of our knowledge, we are the first to apply this type of analysis to an ongoing global pandemic; further, as we focus on the instantaneous oil/stock market linkages, our research will be particularly relevant for policymakers and investors, allowing a prompt detection of energy contagion to inform portfolio diversification and risk management strategies.

\section{Methodology}

\subsection{Pre-filtering of the intraday data}

We pre-filter the series before computing the local Gaussian correlations: as shown by Forbes and Rigobon (2002) the increased volatility of asset returns during crisis periods leads to spurious contagion detection. For this purpose, we apply the multiplicative component GARCH model of Engle and Sokalska (2012), which builds on Andersen and Bollerslev (1997). The conditional variance is a multiplicative product of daily, diurnal, and stochastic intraday volatility. Intraday returns, with subscript $t$ for days and $i$ for intraday observations called bins, are described by the following process:

$$
r_{t, i}=\sqrt{h_{t} s_{i} q_{t, i}} \varepsilon_{t, i} \text { and } \varepsilon_{t, i} \sim N(0,1)
$$

\footnotetext{
${ }^{2}$ The Brent (sweet light) crude oil price fell below \$20 per barrel, (against an average of \$64 in 2019) and the (light) crude WTI dropped into negative territory for the first time in history, at $-\$ 37.63$ per $2020 / 04 / 20$, as a result of a storage scarcity for its physical delivery (Bloomberg news 2020/04/22).
} 
where

$h_{t}$ is the daily variance component,

$s_{i}$ is the diurnal (calendar) variance pattern,

$q_{t, i}$ is the intraday variance component, with $E\left(q_{t, i}\right)=1$, and

$\varepsilon_{t, i}$ is an error term.

For the daily variance component, $h_{t}$, we use a predicted conditional variance from a GARCH model working with a longer sample of daily data. After deflating with the daily variance component, the diurnal component, $s_{i}$, is computed as a sample average of the variance of each bin $i$. After normalizing the returns by daily and diurnal volatility components, the remaining intraday volatility, $q_{t, i}$, is modelled as a $\operatorname{GARCH}(\mathrm{p}, \mathrm{q})$ process with a t-distribution for the innovations.

\subsection{Local Gaussian Correlation}

Local Gaussian correlation has been introduced by Tjøstheim and Hufthammer (2013). The bivariate density $f$ for two return series is usually not Gaussian. The unknown density can be approximated locally with a family of Gaussian distributions. At each point $(x, y)$, the density $f(x, y)$ is approximated by a Gaussian density:

$$
\begin{aligned}
\phi_{x, y}= & \phi\left(u, v, \mu_{1}(x, y), \mu_{2}(x, y), \sigma_{1}(x, y), \sigma_{2}(x, y), \rho(x, y)\right) \\
= & \frac{1}{2 \pi \sigma_{1}(x, y) \sigma_{2}(x, y) \sqrt{1-\rho(x, y)^{2}}} \exp \left\{-\frac{1}{2\left(1-\rho(x, y)^{2}\right)} \times\left[\left(\frac{u-\mu_{1}(x, y)}{\sigma_{1}(x, y)}\right)^{2}+\left(\frac{v-\mu_{2}(x, y)}{\sigma_{2}(x, y)}\right)^{2}\right.\right. \\
& \left.\left.-2 \rho(x, y)\left(\frac{u-\mu_{1}(x, y)}{\sigma_{1}(x, y)}\right)\left(\frac{v-\mu_{2}(x, y)}{\sigma_{2}(x, y)}\right)\right]\right\}
\end{aligned}
$$

The parameters $\mu, \sigma$ and $\rho$ depend on $(x, y)$. The approximation $\phi_{x, y}$ is close to $f$ in a neighbourhood of $(x, y)$. The dependence structure of the pair of random variables is described by the correlation $\rho$. By having a local approximation of the bivariate density, and hence an estimate of a local correlation, the approach is capable of detecting and quantifying nonlinear dependence structures. The Gaussian densities $\phi_{x, y}$ are fitted to $f$ in the neighbourhood of $(x, y)$ with the method of local likelihood (see Tjøstheim and Hufthammer, 2013).

\subsection{Energy Contagion Testing}

Our energy contagion test follows Støve et al. (2014). Let $Y_{t}, t=1, \ldots, T$ be the oil price returns and $X_{t}, t=1, \ldots, T$ the stock market returns in a country. We filter the data for dependence and volatility effects as described in Section 2.1 and denote the standardised returns as $d_{t}=\left(X_{t}^{\prime}, Y_{t}^{\prime}\right)$. The data are split up in a stable non-crisis period (NC) and in a turmoil period (C). Contagion is present if the local correlation function for the turmoil period is significantly above 
the local correlation function for the stable period. The null and alternative hypothesis are:

$$
\begin{aligned}
& H_{0}: \rho_{N C}\left(x_{i}, y_{i}\right)=\rho_{C}\left(x_{i}, y_{i}\right) \quad \text { for } \quad i=1, \ldots, n \quad \text { (no contagion) } \\
& H_{1}: \sum_{i=1}^{n}\left(\rho_{C}\left(x_{i}, y_{i}\right)-\rho_{N C}\left(x_{i}, y_{i}\right)\right)>0 \quad \text { (contagion) }
\end{aligned}
$$

The correlation is computed on a grid $\left(x_{i}, y_{i}\right)$ for $i=1, \ldots, n$, which we choose to be a diagonal grid, where $x_{i}=y_{i}$. A bootstrap is performed, whereby observations $\left(d_{1}, \ldots, d_{T}\right)$ are drawn randomly with replacement. The resample $\left(d_{1}^{*}, \ldots, d_{T}^{*}\right)$ is divided into the time periods $\mathrm{NC}$ and $\mathrm{C}$ and the local correlations on the grid are calculated. A test statistic is computed as follows:

$$
D_{1}^{*}=\frac{1}{n} \sum_{i=1}^{n}\left[\hat{\rho}_{C}^{*}\left(x_{i}, x_{i}\right)-\hat{\rho}_{N C}^{*}\left(x_{i}, x_{i}\right)\right] w\left(x_{i}, x_{i}\right)
$$

where $w_{i}$ is a weight function to concentrate on the region where data points are available.

\section{Data}

We use intraday data (at a 5 minutes frequency) from 2019/10/08 to 2020/04/16 for a sample of oil importers (Japan, China and Sweden) and exporters (Canada, Norway and Russia) ${ }^{3}$. The 5 minute sampling frequency allows to capture the instantaneous links between oil and stock markets, which can be missed at a lower frequency, given the high liquidity of all markets in our sample. We transform the price data into US Dollar and remove overnight returns as customary. Figure 1 shows our series during the identified calm and turbulent phases, and the descriptive statistics of the return series are reported in Table $.2^{4}$

We filter according to the multiplicative component GARCH model of Engle and Sokalska (2012) ${ }^{5}$. To estimate the daily volatility, we use data of daily frequency for a sample of 10 years. All the GARCH coefficients are statistically significant and the GARCH models are stable, see Table .3. Using Ljung-Box tests, we report no autocorrelation in the standardised residuals and some indication of remaining heteroscedasticity for Japan and Norway only.

The turbulent oil market period for our contagion tests begins on 2020/02/23. We note that, even for crises already completed, there is no consensus with respect to their dating (Fry-McKibbin et al., 2014). This is further complicated in our analysis by the lack of a single catalyst event, as the oil crisis resulted from a combination of different events occurring within our window of analysis, such as: (i) the forecasted slump in oil demand (IEA 2020/02/15), (ii) the lack of OPEC/OPEC+ agreement on the implementation of Vienna's (2020/03/05) supply cuts, and (iii) Saudi Arabia's

\footnotetext{
${ }^{3}$ In line with the existing literature, we adopt a split between crisis/non-crisis sample of 1:2.5. The tickers for the national stock markets are: Canada (SPTSX60), Japan (NKY), Russia (IMOEX), China (SHCOMP), Norway (OSEAX) and Sweden (OMX). The oil price is Brent (CO1), as it is the benchmark for two thirds of the global oil supply.

${ }^{4}$ The different number of observations are due to different trading hours per day and different bank holidays.

${ }^{5}$ We use R package 'rugarch', see Ghalanos (2020).
} 

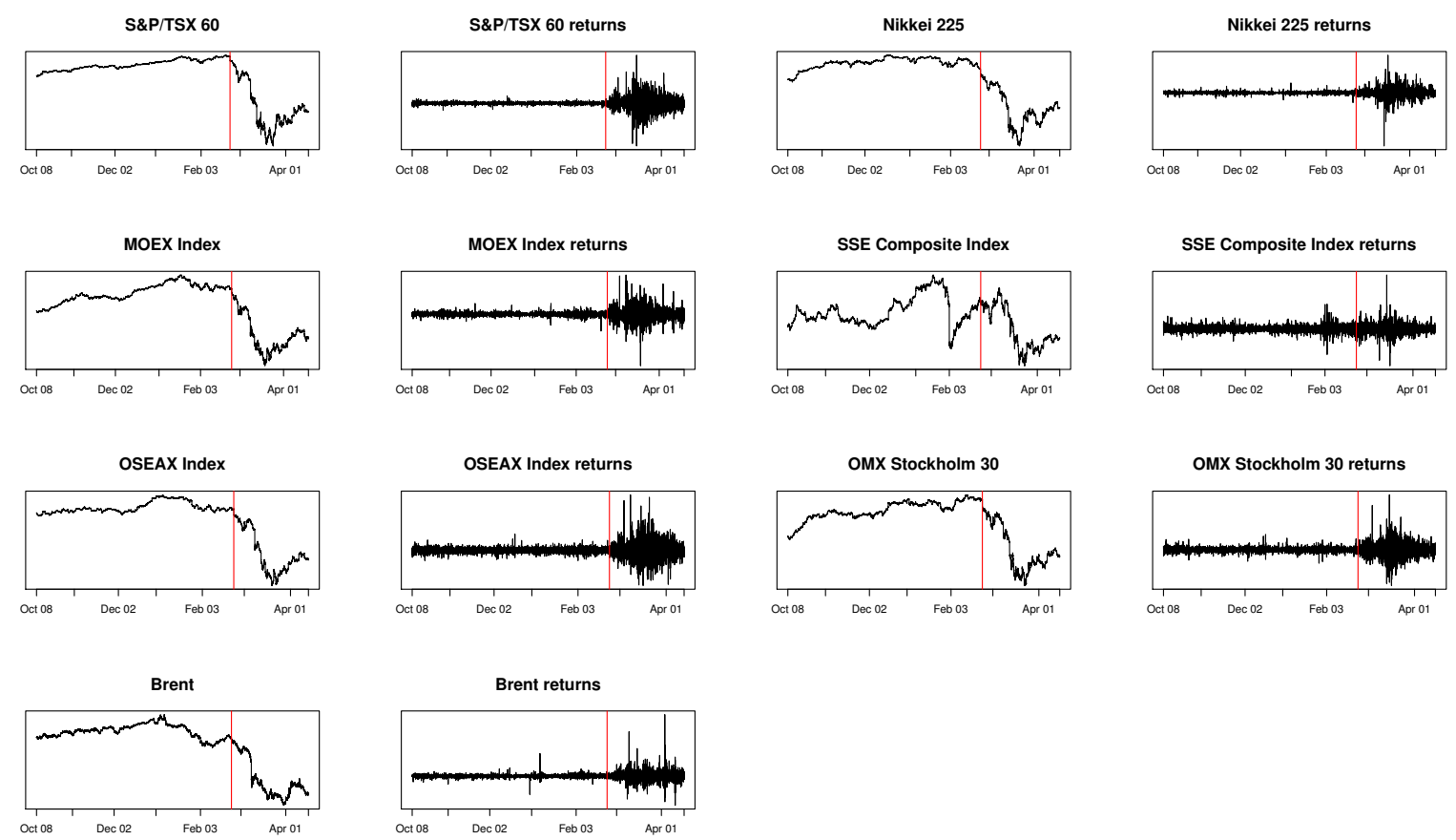

Figure 1: Price indices and return series, 2019/10/08 to 2020/04/16. The beginning of the crisis period, 2020/02/23, is shown with a vertical red line.

announcement of price discounts (2020/03/08). At the same time, COVID-19 (to be declared a global pandemic on 2020/03/11) on the 2020/02/24 counted 79,331 confirmed cases ${ }^{6}$, with the first lockdowns in Europe announced on 2020/02/21 (in Lombard municipalities in Italy).

\section{Empirical Findings}

The oil and stock market returns, filtered with the procedures above described, are then used to compute the local correlations. ${ }^{7}$ We use a version of the local Gaussian approach where the data is transformed to marginal standard normality, so the correlation is computed locally, while the local means and local standard deviations are fixed to 0 and 1 respectively. ${ }^{8}$ We compute the correlations along a grid between percentile 0.01 and 0.99 with 100 grid points. In the contagion tests, we perform 1000 replications in the bootstrap procedure.

Our results in Table 1 show that the null of no energy contagion is comfortably rejected for all countries in our sample: during the identified turbulent sample in the source market, the correlations between oil/stock returns become significantly higher, regardless of the oil importer/exporter status. Russia records the highest correlation in

\footnotetext{
${ }^{6}$ WHO situation report 35/2020.

${ }^{7}$ We perform the computation of local correlation and contagion tests with the help of the R package 'lg', see Otneim (2019).

${ }^{8}$ The method used for bandwidth selection is an approximate "plugin" procedure.
} 
the crisis sample, resulting comparatively more vulnerable, and, at the same time, oil exporters tend to exhibit higher correlations than importers.

Table 1: Correlation and Contagion tests

\begin{tabular}{llccccc} 
country & asset market & non-crisis & crisis & $D_{1}$ & $\mathrm{p}$ value & contagion \\
\hline Canada & S\&P/TSX 60 & 0.206 & 0.424 & 0.218 & 0.000 & yes \\
Japan & Nikkei 225 & 0.198 & 0.378 & 0.180 & 0.000 & yes \\
Russia & MOEX Index & 0.358 & 0.650 & 0.291 & 0.000 & yes \\
China & SSE Composite Index & 0.205 & 0.306 & 0.101 & 0.006 & yes \\
Norway & OSEAX Index & 0.265 & 0.471 & 0.206 & 0.000 & yes \\
Sweden & OMX Stockholm 30 & 0.193 & 0.401 & 0.208 & 0.000 & yes \\
\hline
\end{tabular}

From Figure 2, the correlations during crisis are higher for all segments of the returns distributions (with the exception of China) and there is no evidence of a non-linear dependence structure: oil/stock correlations are not systematically higher or lower when the markets experience extreme shocks (within the given calm/crisis regime).

Taken together, our results confirm the importance of the oil/stock market nexus, identifying an energy contagion based on high frequency data, with oil/stock markets becoming more interdependent at the time of a crisis, in line with (part of) the empirical literature (see, e.g. Xu et al., 2019, Mohaddes and Pesaran, 2017). The consistency of our results across the different countries points to oil and stock markets behaving more as "a market of one".

As our results are based on an exogenously set crisis dating of 23/02/2020, their robustness to alternative datings needs to be carefully verified, in line with the discussion above. For this purpose, we have repeated our tests by considering different potential crisis dating within a $+/-1$ week interval, and our results are qualitatively consistent with the ones presented.

\section{Conclusion}

We have provided evidence of energy contagion in terms of significantly higher oil/stock market correlations during crisis periods in the source market, robust to different crisis dating and consistent across the different countries in our sample and different segments of the returns distribution. Overall, our results confirm the importance of the oil/stock market nexus in the world economy, even at the high frequency of our analysis, and the documented energy contagion will need to be carefully considered by investors and policymakers alike, for asset allocation and risk management strategies: oil and stock markets have been shown to be synchronised, with the consequent reduction of diversification benefits during extreme crises. 

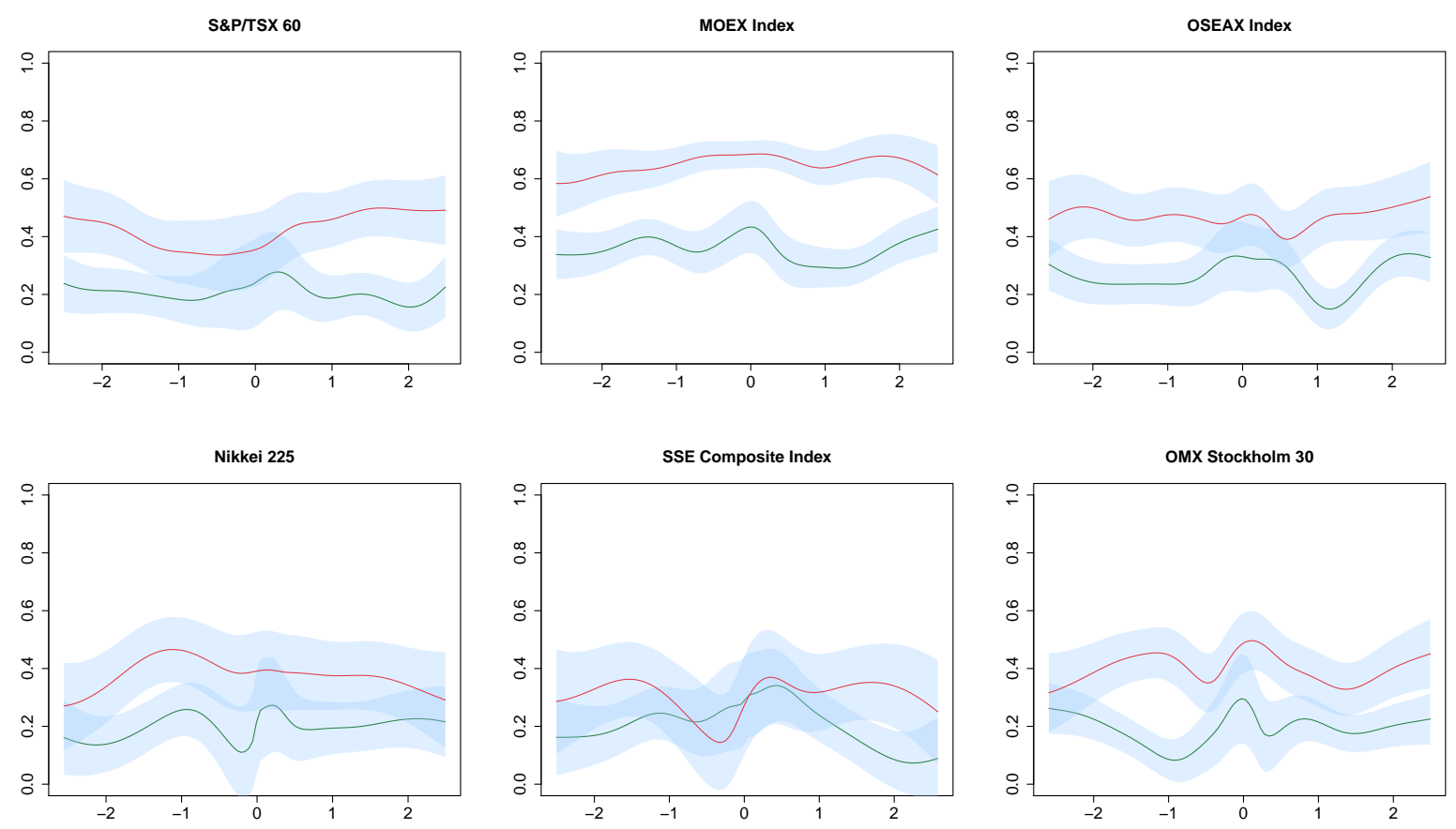

Figure 2: Local Gaussian correlation curves estimated from the equity indices versus Brent in the stable period (green) and crisis period (red), correlations are displayed on the $y$-axis and standardised residuals on the $x$-axis, 95\% significant bands.

\section{References}

Andersen, T.G., Bollerslev, T., 1997. Intraday periodicity and volatility persistence in financial markets. Journal of Empirical Finance 4, 115-158. Bampinas, G., Panagiotidis, T., 2017. Oil and stock markets before and after financial crises: A local Gaussian correlation approach. Journal of Futures Markets 37, 1179-1204.

Engle, R.F., Sokalska, M.E., 2012. Forecasting intraday volatility in the US equity market. Multiplicative component GARCH. Journal of Financial

Econometrics 10, 54-83.

Forbes, K.J., Rigobon, R., 2002. No contagion, only interdependence: Measuring stock market comovements. The Journal of Finance 57, 22232261.

Fry-McKibbin, R., Hsiao, C.Y.L., Tang, C., 2014. Contagion and global financial crises: lessons from nine crisis episodes. Open Economies Review 25, 521-570.

Ghalanos, A., 2020. Package 'rugarch'. R package version 1.4-2.

Hamilton, J.D., 1983. Oil and the Macroeconomy since World War II. Journal of Political Economy 91, 228-248.

Mahadeo, S.M., Heinlein, R., Legrenzi, G.D., 2019. Energy contagion analysis: A new perspective with application to a small petroleum economy. Energy Economics 80, 890-903.

Mohaddes, K., Pesaran, M.H., 2017. Oil prices and the global economy: Is it different this time around? Energy Economics 65, 315-325.

Nguyen, Q.N., Aboura, S., Chevallier, J., Zhang, L., Zhu, B., 2020. Local Gaussian correlations in financial and commodity markets. European Journal of Operational Research .

Otneim, H., 2019. Package 'lg'. R package version 0.4.1.

Reboredo, J.C., Rivera-Castro, M.A., 2014. Wavelet-based evidence of the impact of oil prices on stock returns. International Review of Economics \& Finance 29, 145-176. 
Støve, B., Tjøstheim, D., Hufthammer, K.O., 2014. Using local Gaussian correlation in a nonlinear re-examination of financial contagion. Journal of Empirical Finance 25, 62-82.

Tjøstheim, D., Hufthammer, K.O., 2013. Local Gaussian correlation: A new measure of dependence. Journal of Econometrics 172 , $33-48$.

Wang, Y., Wu, C., Yang, L., 2013. Oil price shocks and stock market activities: Evidence from oil-importing and oil-exporting countries. Journal of Comparative Economics 41, 1220-1239.

Wen, X., Wei, Y., Huang, D., 2012. Measuring contagion between energy market and stock market during financial crisis: A copula approach. Energy Economics 34, 1435 - 1446.

Xu, W., Ma, F., Chen, W., Zhang, B., 2019. Asymmetric volatility spillovers between oil and stock markets: Evidence from China and the United States. Energy Economics 80, 310-320.

Table .2: Descriptive statistics of the return series. Overnight returns removed.

\begin{tabular}{lrrrrrr}
\hline & obs & min & max & range & skew & kurtosis \\
\hline S\&P/TSX 60 & 10247 & -0.02 & 0.02 & 0.05 & 0.30 & 23.88 \\
Nikkei 225 & 7747 & -0.03 & 0.02 & 0.05 & -0.83 & 45.95 \\
MOEX Index & 13493 & -0.03 & 0.02 & 0.05 & 0.28 & 23.53 \\
SSE Composite Index & 6355 & -0.01 & 0.02 & 0.03 & 0.50 & 14.20 \\
OSEAX Index & 11525 & -0.01 & 0.02 & 0.04 & 0.65 & 18.56 \\
OMX Stockholm 30 & 13260 & -0.02 & 0.03 & 0.04 & 0.27 & 20.25 \\
Brent & 34505 & -0.04 & 0.09 & 0.13 & 2.81 & 113.06 \\
\hline
\end{tabular}

Table .3: Intraday GARCH model coefficients and Ljung-Box test results

\begin{tabular}{lccccccc}
\hline & S\&P/TSX 60 & Nikkei 225 & MOEX & SSE Comp & OSEAX & OMX 30 & Brent \\
\hline$A R(1)$ & $-0.022^{*}$ & & & $0.089^{* *}$ & $-0.066^{* *}$ & & $-0.050^{* *}$ \\
$A R(2)$ & & & & $-0.025^{* *}$ & & $-0.015^{* *}$ \\
$\alpha$ & $0.073^{* *}$ & $0.122^{* *}$ & $0.060^{* *}$ & $0.053^{* *}$ & $0.055^{* *}$ & $0.079^{* *}$ & $0.097^{* *}$ \\
$\beta_{1}$ & $0.917^{* *}$ & $0.618^{* *}$ & $0.929^{* *}$ & $0.931^{* *}$ & $0.542^{* *}$ & $0.605^{* *}$ & $0.514^{* *}$ \\
$\beta_{2}$ & & $0.254^{*}$ & & & $0.388^{* *}$ & $0.303^{* *}$ & $0.375^{* *}$ \\
\hline$Q$-Stat(10) res & 7.512 & 5.694 & 14.97 & 14.37 & 9.047 & 3.038 & 24.54 \\
$\mathrm{p}$ value & 0.584 & 0.840 & 0.133 & 0.110 & 0.338 & 0.981 & $0.002^{* *}$ \\
$Q$-Stat(100) res & 91.48 & 94.90 & 115.98 & 126.59 & 96.90 & 91.51 & 98.80 \\
$\mathrm{p}$ value & 0.692 & 0.625 & 0.131 & 0.032 & 0.513 & 0.716 & 0.458 \\
$Q$-Stat(10) res ${ }^{2}$ & 17.66 & 19.68 & 5.438 & 12.14 & 43.20 & 18.47 & 29.17 \\
$\mathrm{p}$ value & $0.024^{*}$ & $0.006^{* *}$ & 0.710 & 0.145 & $0.000^{* *}$ & $0.010^{*}$ & $0.000^{* *}$ \\
$Q$-Stat(100) res & 120.74 & 132.76 & 100.38 & 96.38 & 165.77 & 116.30 & 108.43 \\
p value & 0.059 & $0.009^{* *}$ & 0.414 & 0.527 & $0.000^{* *}$ & 0.088 & 0.201 \\
\hline
\end{tabular}

${ }^{* *}$ significant at $1 \%$ level, ${ }^{*}$ significant at $5 \%$ level. 